\title{
Feminist pedagogy in action: reflections from the front line of feminist activism - the feminist classroom
}

\section{Jenny Louise-Lawrence}

To cite this article: Jenny Louise-Lawrence (2014) Feminist pedagogy in action: reflections from the front line of feminist activism - the feminist classroom, Enhancing Learning in the Social Sciences, 6:1, 29-41, DOI: 10.11120/elss.2014.00022

To link to this article: https://doi.org/10.11120/elss.2014.00022

\section{(c) 2014 A. Rosie, The Higher Education Academy}

\section{册Published online: 15 Dec 2015.}

Submit your article to this journal ๘
Џll Article views: 2765

Q View related articles $\square$

View Crossmark data ¿

Citing articles: 3 View citing articles $\square$ 


\title{
Feminist pedagogy in action: reflections from the front line of feminist activism - the feminist classroom
}

\author{
Jenny Louise-Lawrence \\ Higher Education Academy and Sheffield University
}

Corresponding author:

Dr Jenny Louise-Lawrence, The Higher Education Academy, Innovation Way, York Science Park, Heslington, York YO10 5BR, UK

Email: jenny.louise-lawrence@ @eacademy.ac.uk

\section{Abstract}

How far can feminist pedagogy facilitate a positive learning experience for the student? I explore this question by offering a critical reflection of teaching a Gender Studies module to two cohorts of students: part-time mature and full-time 'traditional' learners. I offer a candid exploration of my personal journey, exposing the strengths and sometimes contradictions found in feminist pedagogic principles. By documenting feminist pedagogy in action I offer a pragmatic approach to its application and refined understanding of it as a method of teaching while attending to feminist pedagogy's core values. My approach empowers the learner, at the same time it enables the tutor to cover module learning outcomes without compromising a feminist agenda. This appropriation is informed by a project designed to put feminist pedagogy (as an approach) and gender studies (as a subject) under critical scrutiny with a view to the refinement of pedagogic practice.

Keywords: feminist pedagogy, reflective learning, critical pedagogy, learning contract, gender studies

\section{Introduction}

Gender studies programmes can provide an emancipatory classroom that recognises student situatedness and challenges the master discourse. This can prove treacherous terrain for the undergraduate who has thus far been programmed to accept an impartial and distant master discourse and the gender studies tutor working to the definitive agenda set by not only the module learning outcomes but also the wider aims of programmes of study. This complexity, in my experience, can be found to disrupt the teaching and learning process. Here I explore how this can be negotiated by offering a critically reflexive account of my teaching part- and full-time students. My personal learning journey is documented through an account of a support network set up for full-time gender studies students. I come to a revised if pragmatic approach to putting feminist pedagogy in action.

The project I explore here was conducted at the start of my academic career. I am inspired to write this piece as I return to pedagogic practice and research and find that, after an 
almost 10 year hiatus, the same pedagogic issues resonate in the critical-pedagogic and feminist-academic communities. My journey will be familiar to those teaching sensitive topics, or puzzling over the practicalities of putting feminist ideals into action in the classroom. I hope my solution to those puzzles is as helpful to you as it has been to me throughout my career in higher education.

\section{Feminist pedagogy}

Feminist pedagogy is commonly thought to be born from either school of education or women's studies departments (Gore 1992). The core principles of feminist pedagogy can be understood to be an affront to normative university pedagogic practice (Wieler 2010): valuing experiential knowledge and reflexivity, the commitment to treating students as knowledgeable, seeing the teacher as learner in the classroom, destabilising the power dynamic between teacher and student (Gore 1992), and approaching teaching as activism.

\section{Gender studies}

Gender studies takes an interdisciplinary approach to the academic interrogation of gendered identities, representations and lived experiences. We can understand gender studies as taking a post-structuralist position: written into the very core of the programme of study is a rigorous and profound challenge to the master discourse. Gender studies can be understood to be a critical pedagogy as it is inherently challenging, critical and political (Darder \& Baltodano 2003) and offers broadly instructive practices to enable the student to critique and problematise any given phenomena (Gore 1992).

The principles of feminist pedagogy and foundations of gender studies resonate with me on a deeply personal level, however I found putting them into practice in the classroom presented some practical as well as ideological difficulties.

\section{Methodology}

I attempt to make sense of my experience by using a critically reflective approach (Brookfield 1995). Bringing the values inherent to feminist pedagogy to the fore helps me establish a departure point for developing my own approach to effective teaching. In order to make a sensible narrative from a fragmented and ongoing evolution I adapt Skelton's reflective triangle, this is a systematic method of self-reflection used in the development of university lecturers (Skelton 2013). I reflect on relevant pedagogic literature, consider my experience of teaching practice and pedagogic study and attempt a methodical investigation of my personal approach to teaching.

\section{My experience of full- and part-time student learning in the gender studies classroom}

When teaching full- and part-time students I am struck by the difference in their approach to learning, their progress, and grasp of the deep theoretical concepts that underpinned their whole programme of study, understanding of the university and academe in general. The full-time students, although more familiar with academic practices and blessed with a sense of belonging to the university alien to their part-time counterparts, did not seem to learn as deeply as the part-time mature students, while the part-time mature students lacked a basic grasp of the core skills and founding knowledge full-time students depended on, so even though their learning was deeper their grades were lower. As a way of exploring the strengths and weaknesses of both groups' approaches to learning I will 
look at the teaching of a core first year/level 4 gender studies module to part-time students then compare that to the teaching of a comparable module to a full-time cohort. I learned a great deal from both groups, which helped in the development of my own approach to feminist pedagogy.

The full-time gender studies programme was multidisciplinary - this was key to my teaching experience. Students could take gender studies as a minor subject in a joint degree with subjects as diverse as philosophy or sociology, or study on gender studies modules as a 'free elective' from almost any programme of study. On the part-time programme students were working toward a social science degree, this module was core to their programme of study. The content of the modules were comparable, but different. The part-time module was more theoretical, focusing on Feminist philosophies, it was taught in 3 hour sessions held in evening classes over a 6 week period. There were, I believe, 10 in the group. The full time module used applied sociology to explore a constructivist account of gender, it was taught over the Autumn semester in weekly lectures and hour long tutorials. There were usually between 50 and 60 students on this module, only 15 to 20 were Gender Studies degree students. Both were level 4 and had the same credit weighting.

The make-up of each gender-studies cohort (the full- and part-time) meant there was no solid cohesion to either of the classes' knowledge. Each student took their own disciplinary-specific approach to the subject (Thomas 1990, Becher 1994). Interdisciplinary teaching raises teaching, learning and assessment issues that are related to each disciplinary area (Squires 1990, 1994, Thomas 1990, Becher 1994); thus the module had to be designed carefully, taught using a certain degree of openness (Race 1998), using active learning (Bonwell \& Eison 1991) with assessments that fitted appropriately the level of study and were meaningful to all.

The individuals within each class had different experiences of learning because of their age (Squires 1990, p146), gender (Fontana 1988, p266, Thomas 1990), and class or cultural background (Fontana 1988, p286, Thomas 1990). These variables affected responses to the course content (Fontana 1988, p266, Squires 1990, p123, Thomas 1990). It should also be noted that the full-time students had been selected to attend their degree course based on their performance at A-level; the part-time students' course was open access, with some students having ended their studies at O-level some 20 plus years previously.

Deeply imbibed patriarchal beliefs are challenged in the feminist classroom. I was led to wonder how students could achieve deep learning in a subject that is in direct opposition to their existing, often subconsciously held ideology or belief systems. Further to this, gender studies courses work from a feminist standpoint that offers a post-structural take on knowledge (knowledge is fluid, ever evolving and can be produced) (Stanley \& Wise 1983). This is destabilising for students whose 'joint' programme offers a master discourse of a static, dominant and authoritative knowledge base.

I found that part-time students did not find this challenge problematic. They were from outside the university and so more open to critiquing academic conventions. The teaching of part-time students greatly enhanced my understanding of effective pedagogy and influenced the development of a student-centred approach that I have gone on to refine and apply in the classroom and staff-development workshops. I will explore first the adoption of feminist pedagogy with a cohort of part-time students before going on to offer an account of this approach with full-time students. 


\section{Feminist pedagogy in the part-time student classroom}

Locating weaknesses or gaps in students' knowledge means module delivery can be more closely geared to address them (Nisbet \& Shucksmith 1988). Given the open-access nature of the part-time course, until I knew otherwise I assumed that my part-time class was starting from the very beginning, not only in terms of academic knowledge but also culture and practice. I went through fundamentals; for example in a class on post-modernism I introduced modernism. I made transparent the module's relevance and relationship to their degree programme and fully explained learning outcomes, explicitly praising students with direct reference to them. I included information on study skills and made sure the class understood they were essential to successful assessment.

\section{Valuing experiential knowledge and reflexivity}

I wanted part-time students to make the leap from 'learning facts' to 'understanding concepts' (Ramsden 1992, p45). I needed to do this in a way that was inclusive and accessible. I was aware that it was important to balance accessible content with an appropriate standard of theoretical depth (Dearing 1997, Randall 2000). I noted that these marginalised students offered personal insight on complex ideologies. When allowed to reflect, the class discussion would lead to a rich dialogue that clearly enhanced the group's understanding. I was trying to facilitate the cognitive link between 'knowing' what is learned in the classroom and 'being' that is their lived experience (Fontana 1988, p279). My goal was for students to reach some depth of academic knowledge (Kornhaber et al. 1990) from personal experience. As defined by feminist practice.

This 'learning orientated' (Taylor 1999, p119) method of managing the class was based on a social constructivist (Kim 2001) student-centred approach common to active learning (Fink 2003) and feminist pedagogy. Understanding students' personal situations and consideration of how adult learners reach cognition (Squires 1990) was central to my lesson planning. I learned through experience that a more dynamic and cohort-specific approach is needed to teach non-traditional learners and/or multidisciplinary groups effectively. Some knowledge of open, active and blended learning is essential to this method. It was at this time that my interest in pedagogic research began. Just like my part-time students I was given a theoretical framework (pedagogy) on which to pin my (teaching) experience and so make better sense of it. It was then that I more consciously developed the active and open method of teaching described and began to fully appreciate the complexity to hand.

\section{Teacher as learner}

I felt that the pedagogue had much to learn from feminist scholarship and research. Exploring ethical, feminist research methods, considering how one negotiated the power imbalance between researcher and the researched seemed to me directly relevant to the classroom dynamic: I would not describe myself as an expert on my research subjects' experience; I merely had a particular, scholarly and theoretic understanding of that experience. This may be different to the research subject. Both are valid. In the class room I was not an expert on $x$ but had a particular understanding of it informed by my academic study. It was my job to share my understanding with the class and in so doing enrich, and for the purposes of their study, help them frame in theoretical terms, their experiential account of it. Moreover, listening to their accounts enriched my understanding of a given phenomenon. 


\section{Destabilising the power dynamic between teacher and learner}

I did not want to be guilty of encouraging students to question the authority of the master discourse, yet recreating an authoritative dynamic in my classroom by privileging my (feminist) accounts of a given topic (Elsworth 1992, p95), or by placing myself as authority or expert. I understood that the critical evaluation of deeply held beliefs is best practiced within a safe and nurturing space (Winwood \& Lamond 2010) and wanted very much to create such a place in my class room.

My approach to teaching at this time could be understood as humanist. I held 'leaderless discussion groups' (Entwistle \& Hounsell 1975, p177) where all contributed (Gore 1992). I found that this equitable, non-hierarchical 'tutorless tutorial' (Entwistle \& Hounsell 1975, p179) had a positive and empowering impact for part-time students, who would offer their account of the reading and subject matter and almost effortlessly present reflective accounts of their lived experience of, for example, sexism in the work place or the division of domestic labour. I would then map their narrative onto the relevant theoretical framework. Together our understanding of the subject evolved (Briggs \& Michaud 1972, p227). This, complemented with the class making the link between 'knowledge' (gender theory) and 'being' (their gendered experience of the world), was good for the class's confidence and learning development (Fontana 1988). I had been involved in feminist activism for many years. The teaching of gender studies and supporting mature part-time learners felt like an extension of this activism. It was enormously exciting watching their evolving knowledge and growing personal empowerment as they began to frame their lives within complex political theories.

\section{Feminist pedagogy in the full-time student classroom}

It is interesting to note how successful this feminist pedagogic approach was with mature learners in the part-time degree programme yet being much less so with traditional students attending full-time courses. The full-time students were often straight from the auto-didactic A-level classroom. They had much invested in tutor-led teaching and, more importantly, their understanding of teaching did not coincide with my practice (Fox 1983, p160). A more student-centred approach was unfamiliar to this group and led to disorderly and sometimes challenging classes. I found with this group that 'attempts to empower can ... have inconsistent effects' (Gore 1992, p60), some students were unable or unwilling to explore the subject in the dynamic way that I had come to value, others took advantage of the class for their own ends.

A small number of students in the group tried to take advantage of my 'tutorless tutorial' by steering the discussion round to an emotive gender issue that, at that time, I felt was not directly relevant to the module's aims and scope. We were looking at representations of gender and how this informs our understanding and expectations of the gendered subject. A small number of students turned the discussion to pornography and began to use disrespectful and inappropriate language. For me this discussion crossed a boundary of social, political and professional acceptability. The language used was highly offensive, their stance, both physical and theoretical, was confrontational and was, I felt then and still do now, motivated by a desire to disrupt and entertain. Possibly this was borne from these young men feeling profoundly challenged by the subject matter, from their feeling unable to engage in a meaningful exploration of the issue.

I found this particular session very difficult, partly because of the sexist opinions being expressed by young men in the class, partly because I felt uncomfortable with my instinct to step in and put a stop to their discussion. I considered this instinct to be my imposing 
my authority onto the group, something traditionally problematised within feminist pedagogy (Luke 1996) and an affront to the privileged voice of the student.

That every student should be respected is essential to ethical and proper teaching. However, in this instance I found reconciling this and my feminist ideals difficult. On considering this particular session later that evening I came to understand that these students needed more guidance, they were stretching my boundaries in some way, I has to consider why this might be. Here I could not sensibly value the experiential knowledge being expressed as their expression was inappropriately phrased and could be seen as an assault on other members of the class, but had to find a way of enlightening these students so that the topic being covered in that session (representations of gender) could be properly explored without some class members becoming divisive, thus ensuring the whole class could progress meaningfully. I needed a way of offering intellectual challenge to the students that was more developmental than confrontational. I learned an invaluable lesson in this session: that effective teaching must be cohort specific (Squires 1990). This cohort-specific approach could mean my dropping my own feminist dogma: adhering blindly to my principles (valuing student experience, stepping down as a figure of authority and destabilising the student-tutor relationship) would have compromised the whole class. We had an agenda to follow, and I had a safe space to create for the whole class. Asking these few students to continue their discussion outside of the class and refocusing the group by holding a closely managed discussion was the right thing to do. Thinking about this several years hence, I can see there could have been things to learn from their emotive dialogue. Probably I would manage this situation differently now, and offer a firm steer to the conversation and ask the students to better express their ideas without a direct request for them to continue that particular strain of thought outside the class.

It is also interesting to note that I can now acknowledge that tutors are the same kind of thinking feeling and possibly vulnerable subject as her or his students. We are as open to rogue emotions as the class. This particular topic was an issue that was to me sensitive, for another tutor it may be different.

\section{Reflexivity}

As the semester progressed I steered this class toward personal reflection with the aim of allowing students to make connections between their knowledge of $x$ and their lived experience. I hoped that making connections personal would facilitate a deep learning and understanding (Moon 2002), which I explained to the class. However, these students struggled to reflect on their lived experience.

I encouraged their engagement by asking how their discipline would approach a given issue. This was a more productive method. It was interesting for me to hear how other disciplines approached a given topic, certainly my enthusiasm in hearing their academic accounts excited students and encouraged their participation. In this way there was a mutual 'curiosity and ... two way exchange' (Briggs \& Michaud 1972, p227). However, the sense of valuing personal reflection and experiential knowledge was not working in moving class discussion forward. Students resisted personal reflection and found offering experiential accounts difficult. I would have to step up and draw the class onwards to ensure that each topic was fully explored and the learning outcomes of the module met. Although students were doing the reading and engaging as far as they could with the subject matter I did not think that they were making the same deep learning connections that my part-time cohort had. 
Watching these young adults attempt a more reflective approach to learning posed an ethical problem. Were the class vulnerable? I came to recognise as central to the progress of gender studies modules the importance of creating safety in the classroom. As it is sensitive, the subject touches on many delicate areas that can be understood as triggers for difficult emotions (Thomas 1990, p21, Lowe \& Jones 2010). I had to be responsible and take care of the students in my class with regard to this.

I found that I needed a means of addressing the following issues: how to steer group discussion to cover course content without stepping up as an authority figure; considering the students as knowledgeable when I disagreed with their position (and indeed their position contradicted the module learning outcomes); how to support students in making personal reflection and critical re-evaluation of their thinking without imposing a feminist dogma.

\section{Strategy to support deep learning in the gender studies classroom}

I won funding to run a short project to support gender studies students. This funding came through the HEFCE supported Widening Participation fund. My aims were clear: To offer full-time students the time and space to reflect on their studies as deeply and effectively as their part-time counterparts and enable a dialogic approach to learning. The project started the following academic year, so I would be working with a new cohort of students studying on the full-time module.

\section{Project design}

I scheduled regular meetings for full-time students registered on a joint gender studies degree programme. I hoped to provide a safe space where students could reflect freely and frankly on their studies, placing their knowledge and understanding as central to their academic development, allowing them to recognise their personal, academic and political progress and explore how far I could destabilise the teacher-student power dynamic without compromising the meaningful progress of the course. I planned to take an active learning approach and prepared role-play sessions (for example setting a scene where one participant takes the position of a headteacher, another that of a member of staff looking for promotion within their primary school), selected current stories from the media (the number of female members of parliament and an ongoing media interest in the Blairite approach to increasing female representation) or university life (an incident involving the Student Union Women's officer) for the basis of discussion and brought readings to dissect (passages from texts as varied as Nick Hornsby to segments from the Students' Union news bulletin). In the past I had been involved with women's groups and this informed my approach. Creating a safe space to explore, being creative and open to the development of the group were central to my thinking. My challenge was how to do this with a formal agenda: covering the module and degree programme's aims and academic ambitions.

The group was open to students enrolled on gender studies degree programmes only. We met weekly in my office. I split the 18-strong cohort into two smaller groups to try to manage the discussions and encourage everyone to speak. The sessions were scheduled to be directly after a core module lecture. I had the time checked by the central timetabling office to make sure all students would be free to attend. I thought this scheduling would be efficient for students with extra-university responsibilities 
and demands (they would be on campus for the core module, so additional travel costs and time were not needed).

At our first session I set a relaxed and focused scene by making tea for all, putting a sign on the door 'Do Not Disturb' shutting down the computer and redirecting calls. I insisted that we sit in a circle and turn off mobile devises. I wanted students to know this time was precious and was not to be wasted. I ensured confidentiality and explained that these sessions were to support their learning and to assist me in understanding how to better support future learners. I clearly articulated my position as fellow, not authority. This felt to me like activism. I wanted to empower and enable the students, have them grow academically and personally through their rigorous exploration of gender.

In the sessions we would start with the literature/role-play or story from the news. I would ask what the group thought of the piece then for more personal reflections. I became adept at theorising their reflections, framing them within an academic context, then segueing into how students felt they could express this academically. I hoped that, as their confidence increased and learning progressed, the group would start to make these connections themselves. Some did, however others struggled and required more nurturing support.

Ethical thinking was at the heart of my practice (see Endnote). I was fresh from reflective learning training course. I prepared a number of strategies to manage the sessions should they become too difficult, for example, reminding students they need only speak of personal experience if they felt they wanted to, and how to manage gently the overly exercised contributor. I armed myself with knowledge of the relevant support available to students both on and off campus (counselling services, financial support, women's groups and other local support networks).

I encountered a certain degree of 'role strain' (Hayes-Smith et al. 2010) in these sessions. I was aware that where facilitating learning ended and counselling began may be an issue, and thought I was prepared. However, the emotional and intellectual intensity of some of the sessions was unexpected. Some students started to use the sessions to explore painful personal histories. From my own experience of studying gender I was familiar with tears in the classroom and recognised that emotion would run high when teaching sensitive topics (Caswell 2010). The greatest challenge for me was how to facilitate these reflections and make deep learning connections without wreaking some kind of havoc in the students' interior lives. Further to this, it is recognised that female teaching staff can often tumble into nurturing students (Walkerdine 1992). I wanted to avoid this gendered stereotype for reasons beyond the mere political.

It became clear to me that my role was to facilitate learning, yet I had a responsibility to my students. Feminist pedagogy seemed to call for more than being an effective educator. What of the care I had to take when stirring up the class in our exploration of sensitive issues? By exposing their personal histories some students illustrated their deep engagement with the subject matter, but at what cost? I was not professionally qualified or, I felt, appropriately competent in a therapeutic role. I felt personally responsible for students who had been upset by some of the subjects we discussed. Further, containing the over exercised student or dominating individual was deeply uncomfortable when she or he was exploring personal history, as was witnessing students disagreeing over an issue when the subject had been made so very personal. I needed to find a balance between encouraging personal reflection, ensuring students did not use the sessions for therapeutic purposes and acting as a caring educator without tumbling into the role of therapist.

To manage these complexities I adopted a 'learning contract' approach for these sessions. In support of some sensitive research that I was conducting, I had recently studied on a counselling skills course. This course used a learning contract to enable the class to 
proceed with focus and rigour. Such contracts are often used in courses that cover sensitive issues, eg nursing (Richardson 1987) and is very common in the USA. I presented the idea of the contract to the students. This was done verbally with the help of a white board. At the time students did not want to amend anything and we all agreed to abide by its core ambition: to cover the course content with respect for the subject matter and each other. This contract was addressed verbally at the beginning of the session; I asked the class to be respectful, supportive and honest in the sessions and flagged where to go for support should an issue trigger distress. I also made clear that we may offer different opinions, and that we should all respect each position, and positions may change as our understanding evolved. I also suggested that I steer the conversation, explaining I could then ensure all the key aspects of each topic would be covered. I would refer back to this agreement should our discussions become unwieldy. This contract also supported me and made me feel safe when managing a delicate or sometimes volatile dynamic.

For both groups this contractual approach seemed to give us a passport to meaningful development. For the students unfamiliar with a student-centred approach to learning it offered them a navigational tool for the alien terrain of the feminist classroom, for me as facilitator I felt (and still feel; I have continued to use learning contracts throughout my career) that it provided a transparent framework with which to manage the class. It served to empower the group and helped the students recognise their responsibility for their own learning and that of the whole group. (For a breakdown of data tracking the positive impact of the learning contract see Lemieux 2001.)

I found as the weeks progressed that students embraced this interactive approach to learning and I needed to steer less and less. Discussions began to flow meaningfully without my asking questions or leading the group. I wondered if an evolutionary approach would better serve a class unfamiliar with active, student-centred or dialogic learning. By this I mean an approach where tutors start the module offering active steer but as the group begins to develop it's own life and dynamic she or he can begin to step back, interjecting where clarification is needed.

\section{Student feedback}

Feedback from the group (blind evaluation forms with free text responses) was positive. Students recognised in themselves improved reflection and critical self-analysis. One student said in response to 'What did you find most challenging about the Gender Studies Group?':

I felt embarrassed talking about some of the private things we covered.

I couldn't see how it was relevant to my university work. Jennies [sic] bringing our reading into our conversation helped me connect my personal with the political. [sic]

The groups' growing emotional maturity was evident in the classroom, they were more respectful of each-other's views, less defensive of their own position. A student put it beautifully (in response to 'What have you most enjoyed?'):

Changing my mind ... and it being alright.

Their academic skills were also enhanced in that they were beginning to think more critically and were gaining confidence in this detraction from the master discourse(s) presented to them in other modules.

I have learned to really think about my studies. Not just learn and listen. But think long and hard about what we are learning means [sic]. Not just to me but to others. 
I met with this group for a 12-week semester. By the end of that semester we knew each other very well. In the final session we talked about the meetings and what we had learned, I asked them what they thought about our appropriation and modification of feminist approaches to teaching and learning. I thought I had learned something about setting realistic boundaries to what can be expected and is appropriate in the classroom. This was of great interest to the group and led to an animated discussion of the personal as political (see quote above). One student said during this discussion, 'I liked the contract, it helped me understand what we were trying to do and made everything clear'. This comment speaks volumes: for those unfamiliar with a student-centred approach to learning the contract served as a map to help them navigate the strange terrain of the feminist classroom.

The group had set up a strong support network among themselves and planned to continue to meet to explore their understanding of gender studies.

\section{A pragmatic approach to a feminist ideal}

So, how far was I able to put the core principles of feminist pedagogy into practice? I have shown how the valuing of the experiential knowledge of the student can be difficult if that expressed knowledge is a direct affront to the learning outcomes the class is working towards, that reflexivity brings with it ethical and practical problems not easily managed in the classroom, destabilising the power dynamic between teacher and student can compromise the class's prime agenda: to cover the learning outcomes of a module or class. However, seeing the teacher as learner in the classroom is clearly valuable: we never cease to learn, to have our knowledge enriched and enhanced by those we experience.

I found that refining feminist principles enabled an effective approach to teaching and learning that I use today.

\section{Valuing experience: contained reflexivity}

The students' experience should always be valued, teaching staff have much to learn from the lived experiences of their classes. This approach empowers the student, and facilitates their making deep learning connections. Reflection is key to both student and tutor development. Creating a safe space for reflection and critical self-evaluation while at the same time establishing firm and appropriate boundaries can be managed with a learning contract. The setting of boundaries allows the class to work within the remit of the tutor's professional competencies and thus protects the students' personal wellbeing without compromising academic progress. For those unfamiliar with reflective learning it provides a stabilising framework.

\section{Destabilising the tutor-student power dynamic: keeping on track}

The destabilising of the student-tutor power dynamic is only partially possible if a course is to progress meaningfully and the student is to succeed academically. It is the responsibility of the tutor to ensure the course is fully and thoroughly covered, that reflections are couched meaningfully within theory and that students learn how to frame their reflections academically. This can be done with some steer, and does not necessarily mean the replacing of one dogma with another. It puts the tutor in the position of facilitator rather than authority figure, though she or he must have some kind of handle on the class and manage its progression. As students grow more familiar with each other, 
with this approach to learning and the subject matter the tutor can begin to step back and provide less and less steer, interjecting when clarification is needed. So, a staged and cohort-specific approach to the tutor-student dynamic is called for.

\section{Critical thinking: celebrating changing positions}

The critical approach inherent to the feminist classroom empowers and enables the student. Critical reasoning is crucial to academic competence. Gender studies students work on critiquing the status quo from the first. The explicit understanding that intellectual growth will inevitably lead to a changed ideological framework gives students the freedom to explore their own thinking about the world. The 'growing theory' of learning recognising the learning process enhances the students' personal development (Fox 1983). It leads to deep thinking, deep learning and enhances their learning experience.

\section{Concluding thoughts}

In conclusion, feminist pedagogy provided a rigorous departure point for effective teaching. Refining this style of pedagogy to suit the cohort, the subject and that specific session empowers the students and tutor and brings us to a point where the shared learning experience can be free to evolve within the remit of the aims and objectives of the course.

\section{Endnotes}

This work was not at the time deemed eligible for ethical scrutiny or formal ethical approval, it was funded through the university's Widening Participation Fund and had been approved by that and the Student Welfare committees.

\section{References}

Becher, T. (1994) The significance of disciplinary differences. Studies in Higher Education $19(2), 151-161$.

Bonwell, C.C. and Eison, J.A. (1991) Active learning: creating excitement in the classroom (ERIC Digest, ASHE-ERIC Higher Education Reports). Washington, DC: The George Washington University.

Briggs, A. and Michaud, G. (1972) Problems and Resolutions. In Interdisciplinarity: Problems of teaching and research. Proceedings of seminar on interdisciplinarity in universities, organized by the center for educational research and innovation. (eds. L. Apostel, G. Berger, A. Briggs and G. Michaud). France: Organization for Economic Co-operation and Development.

Brookfield, S.D. (1995) Becoming a critically reflective teacher (Jossey-Bass Higher and Adult Education Series). San Francisco, CA: Jossey-Bass.

Caswell, G. (2010) Teaching death studies: reflections from the classroom. Enhancing Learning in the Social Sciences 2 (3), doi:10.11120/elss.2010.02030009.

Darder, A. and Baltodano, M. (2003) The critical pedagogy reader (ed. R.D. Torres). New York, NY: Routledge/Falmer.

Dearing, R. (1997) Higher education in the learning society (National Committee Inquiry into Higher Education, Summary report). London: NCHE. 
Entwistle, N.J. and Hounsell, D. (eds.) (1975) How students learn. Lancaster,UK: Institute for Research and Development in Post-Compulsory Education, University of Lancaster.

Elsworth, E. (1992) Why doesn't this feel empowering? Working through the repressive myths of critical pedagogy. In Feminisms and critical pedagogy (eds. C. Luke and J. Gore), pp92-119. London: Routledge.

Fink, L.D. (2003) Creating significant learning experiences: an integrated approach to designing college courses. San Francisco, CA: Jossey-Bass.

Fontana, D. (1988) Psychology for teachers (3rd ed.). Leicester: British Psychological Society.

Fox, D. (1983) Personal theories of teaching. Studies in Higher Education 8 (2), 151-163.

Gardner, H. (1990) Multiple intelligences: the theory in practice. New York, NY: Basic Books.

Gore, J. (1992) What can we do for you? Struggling over empowerment in critical and feminist pedagogy. In Feminisms and critical pedagogy (eds. C. Luke and J. Gore), pp54-73. London: Routledge.

Hayes-Smith, R., Richards, T.R. and Branch, K.A. (2010) 'But I'm not a counselor': the nature of role strain experienced by female professors when a student discloses sexual assault and intimate partner violence. Enhancing Learning in the Social Sciences 2 (3), doi:10.11120/elss.2010.02030006.

Kim, B. (2001) Social constructivism. Emerging perspectives on learning, teaching, and technology, 1-8.

Kornhaber, M., Krechevsky, M. and Gardner, H. (1990) Engaging intelligence. Educational Psychologist 25 (3-4), 177-199.

Lemieux, C.M. (2001) Learning contracts in the classroom: tools for empowerment and responsibility. Social Work Education 20 (2), 263-276.

Lowe, P. and Jones, H. (2010) Teaching and learning sensitive topics. Enhancing Learning in the Social Sciences 2 (3), doi:10.11120/elss.2010.02030001.

Luke, C. (1996) Feminist pedagogy theory: reflections on power and authority. Educational Theory 46 (3), 283-302.

Moon, J. (2002) Learning journals: a handbook for academics, students and professional development. London: Kogan Page.

Nisbet, J. and Shucksmith, J. (1988) Learning strategies. London: Routledge.

Race, P. (1998) Five hundred tips for open and flexible learning. Hove, UK:

Psychology Press.

Ramsden, P. (1992) Learning to teach in higher education. London: Routledge.

Randall, J. (2000) A new framework for quality assurance. Higher Education Digest. Spring 2000, pp2-3.

Richardson, S. (1987) Implementing contract learning in a senior nursing practicum. Journal of Advanced Nursing 12 (2), 201-206.

Skelton, A. (2013) Teaching, learning and the changing nature of higher education. Notes from a lecture given at Sheffield University, 18th September 2013.

Squires, G. (1990) First degrees: the undergraduate curriculum. Philadelphia, PA:

The Society for Research into Higher Education/Open University Press.

Squires, G. (1994) A new model of teaching and training. Hull: University of Hull, Education and Development Team. 
Stanley, L. and Wise, S. (1983) Breaking out: feminist consciousness and feminist research. London, UK: Routledge \& Kegan Paul.

Taylor, P.G. (1999) Making sense of academic life: academics, universities and change. Philadelphia, PA: The Society for Research into Higher Education/Open University Press.

Thomas, K. (1990) Gender and the subject in higher education. Philadelphia, PA:

The Society for Research into Higher Education/Open University Press.

Walkerdine, V. (1992) Progressive Pedagogy and Political Struggle. In Feminisms and Critical Pedagogy (eds. C. Luke and J. Gore), pp15-24. New York: Routledge.

Wieler, K. (2010) Friere and a feminist pedagogy of difference. Harvard Education Review 61 (4), 449-475.

Winwood, J. and Lamond, C. (2010) When are they going to tell me what to do? Tackling sensitive topics through the development of self-efficacy. Enhancing Learning in the Social Sciences 2 (3), doi:10.11120/elss.2010.02030011. 